\title{
Analysis of otorhinolaryngology related surgeries performed in a tertiary care center over four years' period
}

\author{
Krishna Prasad Koirala \\ Associate Professor, Department of ENT-HNS, Manipal College of Medical Sciences Phulbari Campus, Pokhara, Nepal
}

A B S T R A C T

Background: The trend of ENT related surgeries worldwide have changed over the years due to better understanding of the disease process, patient awareness, surgical workshops, conferences, etc. Many ENT related hospitals and subspecialty centers of surgical excellence have been established in different parts of our country in recent years. There have been substantial patient preferences to specialty than general hospitals. Aims and Objectives: The current study was designed to compare different surgeries performed during the four years period from 2015 to 2018 and observe the changing trends in common surgeries during these years. Materials and Methods: This is a prospective study carried out in the Department of ENT- HNS, Manipal Teaching Hospital, Pokhara, Nepal from $1^{\text {st }}$ Jan 2015 to $31^{\text {st }}$ Dec 2018. Patients of all age and both sex operated under the department of ENT were included in the study. Data wereanalysed and results were published to look for the changing trends of different types of surgeries. Results: Out of 945 surgeries performed during these 4 years, major surgeries were rigid esophagoscopy, septoplasty, myringoplasty, mastoid exploration, tonsillectomy and endoscopic sinus surgery. Commonly performed intermediate and minor surgery was excision of minor and intermediate head and neck lesions. Excision was in the rise, esophagoscopy and myringoplasty were almost constant and septoplasty and modified radical mastoidectomy were in the decreasing trend $(p<0.05)$. Conclusion: In our study, the trend of performing major otolaryngology and head and neck surgeries in our institution is in the descending trends in the recent years after 2015.Common ENT related surgeries shall be in the descending trend while specialty services will be ever progressing in the future.
Access this article online

Website:

http://nepjol.info/index.php/AJMS DOI: 10.3126/ajms.v11i3.27399

E-ISSN: 2091-0576

P-ISSN: 2467-9100

Copyright (c) 2020 Asian Journal of Medical Sciences

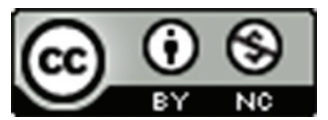

This work is licensed under a Creative Commons Attribution-NonCommercial 4.0 International License.

Key words: Increasing trends; Decreasing trends; Surgical trends; Otorhinolaryngology

\section{INTRODUCTION}

Otorhinolaryngology field of medicine deals with both medicine and surgery. Different types of otorhinolaryngology related surgeries, both major and minor, are performed by the Ear, Nose and Throat (ENT) surgeons daily. The trend of ENT related surgeries has advanced in the recent years. The causes might be better understanding of the disease process, patient awareness, surgical workshop and conferences, availability of better anesthetic techniques and introduction of day care surgery. Although tonsillectomywas one of the most commonly performed ENT surgery worldwide, the rate of tonsillectomy has sharply declined by 34\% in Germany from the span of 2012 to $2016{ }^{1,2}$ There have been decline in adenotonsillectomy also with an appreciation that child acquires immunity due to minor recurrent upper respiratory tract infections. ${ }^{3}$ Similar trends are observed in English population. ${ }^{4}$ Adenotonsillectomy rates have also been found in declining status among children aged $4-15$ year in England. ${ }^{5}$ However, in Sweden, sharp trends of increase was reported in tonsillectomy rates from 22/10 000 person years in 1987 to $47 / 10000$ in 2013 . The most marked increase was noted in children between $1-3$ years of age. ${ }^{6}$

Hospital admissions for patients with an esophageal foreign body have also been reported in the decline in recent years. ${ }^{7}$ Mastoid surgeries are also in a decreasing 
trend in the western countries although data are lacking in the developing countries. ${ }^{8}$ There are reports of significant improvement in performance of sinus surgeries in comparison to previous years as the anatomy is well understood and newer techniques have evolved. ${ }^{9}, 10$ Although the technique of performing ENT surgeries is more or less same, the technology has improved a lot in the recent years. Therefore more complex ENT surgeries have become much simpler. Surgeries for infective diseases have sharply declined and the indications have been shifted from infective to non-infective conditions in the western countries. However, developing countries still face problems with infectious conditions.

Since, Nepal is a developing country we have both infective and non-infective conditions for otorhinolaryngology related surgeries. ENT related surgeries were limited in few centers of Nepal till the recent past. As per our understanding of disease and better superspecialty training in the recent years, many centers of ENT related surgical excellence are now established in different regions of the country. Newly established centers have attracted more patients than general hospitals due to upgraded and advanced surgical techniques.

Our centre is a tertiary care hospital in western region of Nepal providing different ENT related surgeries for the past 15 years. We have been performing many routine as well as emergency ENT related day care surgeries and in patient surgeries in a routine basis. Due to availability of different subspecialties within otolaryngology, there have been substantial patient preferences to specialty than general hospitals. For example, cancer patients tend to go to the head and neck cancer surgical hospitals, patients with ear related problems go to the ear surgery hospitals and nose related patients prefer centers with nasal excellence. Being a medical college and teaching hospital, we have been providing ear, nose and throat related surgeries in our hospital.

We did not get any studies regarding changing trends in ENT related surgeries carried out in the general and teaching hospitals from Nepal. In this study we have attempted to analyse the changing trends in ENT related surgeries in a tertiary care center in the last four years. We hope that this study would be useful for the new ENT doctors to choose their field of fellowship and will also find out the recent trends in the field of otorhinolaryngology surgery in our set up.

\section{Aims and objective}

- To identify the otorhinolaryngology related surgeries performed in years 2015, 2016, 2017 and 2018.

- To compare different surgeries performed during the study period.
- To look for the increasing or decreasing trends in major surgeries during these years.

\section{MATERIALS AND METHODS}

This is a prospective study carried out in the Department of ENT- HNS, Manipal Teaching Hospital from Jan $1^{\text {st }} 2015$ to $31^{\text {st }}$ Dec 2018.Patients of all age and both sex operated under the department of ENT in our hospital during the study period were included in the study. They were categorized according to surgeries performed in ear, nose throat, head and neck and major and minor ones. Data were analysed with the help of SPSS software and results were published to look for the changing trends of different types and categories of surgeries.

\section{RESULTS}

A total of 945 patients underwent both major and minor surgeries during these 4 years. The average number of surgeries performed per year was 236.25. Of which 422 were males and 523 were females. Male to female ratio was 0.8:1.Figure 1 shows male to female ratio of the surgeries performed in these 4 years.

Most commonly performed major procedures were rigid esophagoscopy, septoplasty, myringoplasty, mastoid exploration, tonsillectomy and endoscopic sinus surgeries. Other less commonly performed major surgeries were direct laryngoscopy and biopsy, thyroid surgeries, rigid bronchoscopy and foreign body removal, Sistrunk's operation, parotid surgery and maxillectomy.

Most commonly performed intermediate and minor surgery wereexcision of minor and intermediate head and neck lesions in general. Figure 2 depicts the pattern of common surgeries performed during these four years.

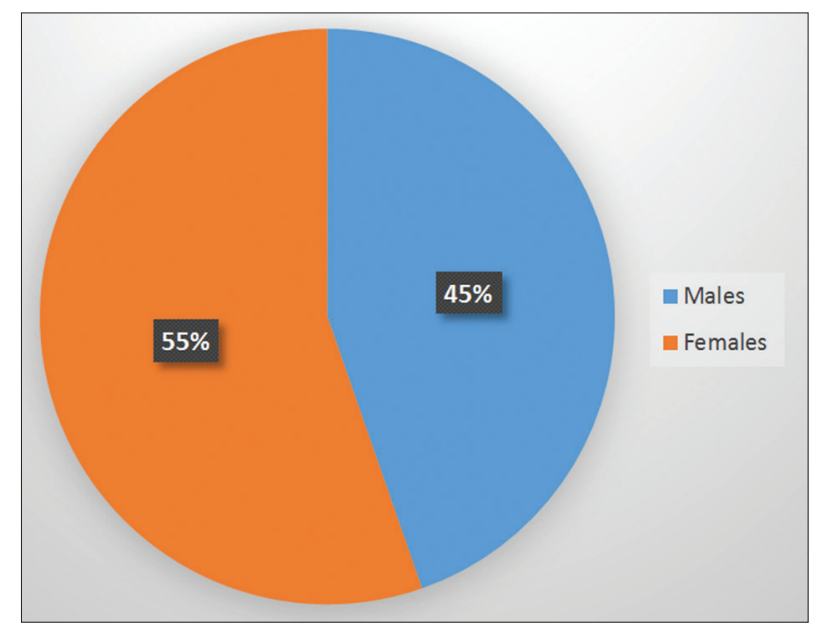

Figure 1: Number of surgeries according to sex $(n=945)$ 


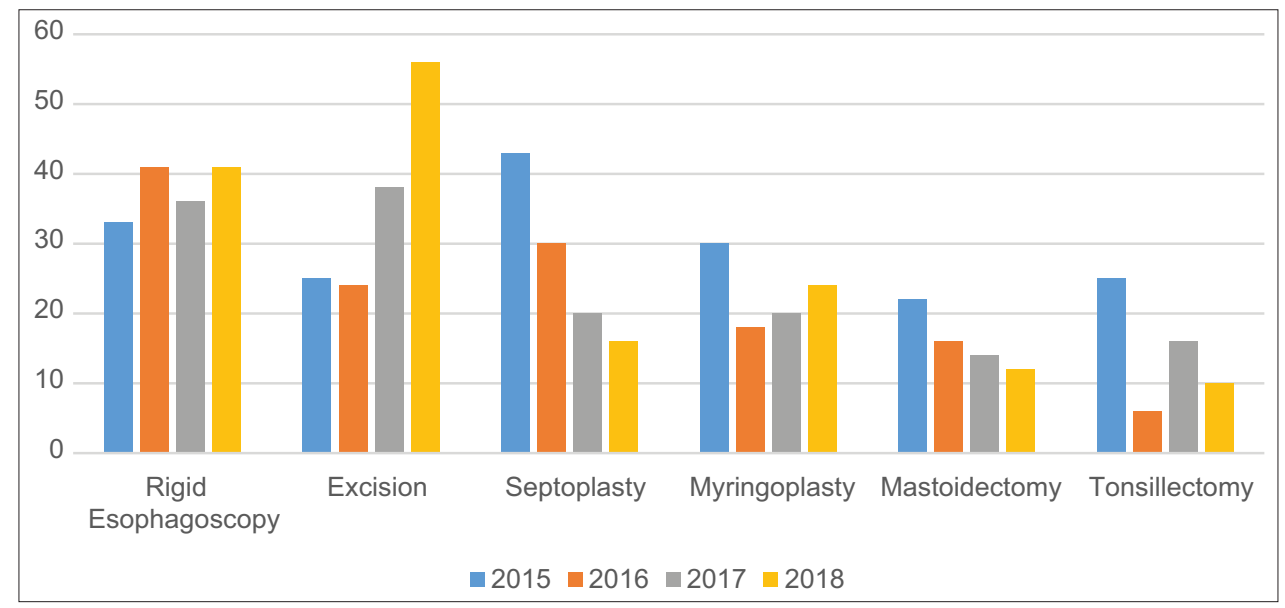

Figure 2: Number of major surgeries performed each year for 4 cosecutive years

There was not much change in number of overall major surgeries performed in these 4 years. The maximum surgeries were performed in 2015 and 2018, and least number of surgeries were performed in 2016 (Figure 3).

Rigid esophagoscopy for foreign bodies in the esophagus was the most common of all the procedures. Its trend was not changing over the years. Second to esophagoscopy was the excision of minor/intermediate head and neck lesions including lymph nodes. The trend of head and neck minor procedures had increased every year in last 4 years.It was the most common surgery performed in 2018. Although septoplasty was the third most common surgery performed in last 4 years, its trend was decreasing each year from 43 in 2015 to 16 in 2018. Myringoplasty was the fourth common surgery which was almost constant in all the years. Mastoid surgeries were in the decreasing trend. There was rapid decline in tonsillectomy, endoscopic sinus surgery and direct laryngoscopy and biopsy over the years.

Table 1 depicts the common surgeries performed in 4 years duration. Statistical analysis was done amongst the common surgeries. The test was significant with the $p$ value of $<0.05$. This shows that excision was in the rise, esophagoscopy and myringoplasty were almost constant and septoplasty and modified radical mastoidectomy were in the decreasing trend.

\section{DISCUSSIONS}

The specialty of otorhinolaryngology is a fusionof otology being surgery and laryngologybeing medicine joined together in the early $20^{\text {th }}$ century. This specialty has undergone dramatic development over the last 30 yearsdue to advances in treatment, better surgical skills and teaching learning experiences. ${ }^{3}$

We have undertaken this study to observe if there are any changing trends in otorhinolaryngology related surgeries

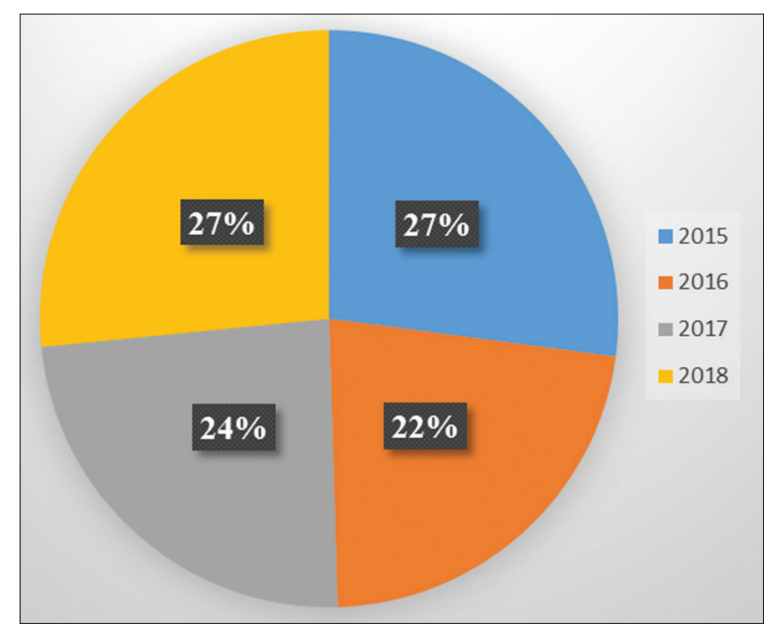

Figure 3: Number of surgeries performed per year

in the recent years.During our four years study period, there were 945 major and minor surgeries. Of them, rigid esophagoscopy and foreign body removal from the esophagus was the most commonly performed surgical procedure. This is an emergency procedure and gold standard to remove foreign bodies from the esophagus. However, in the recent years, few people opt for flexible esophagoscopy for removal of blunt foreign bodies from the esophagus. As flexible endoscopy is an outpatient procedure which does not require general anesthesia, it is taking popularity for selected patients with blunt foreign bodies. Mondal et al and Birk et al have given more emphasis to flexible esophagoscopy than rigid esophagoscopy to remove foreign bodies from the esophagus. ${ }^{11,12}$ We have also started to refer few of our patients to gastrologist for removal of blunt foreign bodies from the esophagus. So in the coming years, flexible esophagoscopy may gain popularity for removal of selected foreign bodies from the esophagus.

Excision of minor to intermediate head and neck lesions was the second most surgical procedure carried in these 
Table 1: Statistics of common surgeries performed during the study period

\begin{tabular}{lccccc} 
& Year 2015 & Year 2016 & Year 2017 & Year 2018 & Total \\
\hline Esopagoscopy & $33(41.33)[1.68]$ & $41(34.85)[1.09]$ & $36(34.58)[0.06]$ & $41(40.25)[0.01]$ & 151 \\
Excision & $25(39.14)[5.11]$ & $24(33.00)[2.45]$ & $38(32.74)[0.84]$ & $56(38.12)[8.39]$ & 143 \\
Septoplasty & $43(29.83)[5.81]$ & $30(25.15)[0.93]$ & $20(24.96)[0.99]$ & $16(29.05)[5.86]$ & 109 \\
Myringoplasty & $30(25.18)[0.92]$ & $18(21.23)[0.49]$ & $20(21.07)[0.05]$ & $24(24.52)[0.01]$ & 92 \\
MRM & $22(17.52)[1.15]$ & $16(14.77)[0.10]$ & $14(14.65)[0.03]$ & $12(17.06)[1.50]$ & 64 \\
Total & 153 & 129 & 128 & 149 & 559 \\
\hline
\end{tabular}

The chi-square statistic is 37.4881. The $p$-value is .000186. The result is significant at $p<.05$.

years. Although not specified in the study, lymph nodes, minor salivary glands, mucus retention cysts, thyroglossal cysts, incision and drainage were all covered under this heading. There is steady increase in these studies every year. It might be due to patient awareness and also fear of cancers in the swellings so that patients will seek the treatment as soon as possible.

Third common surgery performed was septoplasty. There was continuous decline of the septal surgery in our hospital in the years under study. Initially septal surgeries were performed in our center only. For last few years, this surgery is being performed in other centers of the city, too. This might be a reason behind the fall of septal surgery in our institution. There is no global data available to compare the trends in septal surgery. There was statistically significant decline of septoplasty $(\mathrm{p}=0.0018)$ in comparison to other surgeries.

Endoscopic sinus surgery along with septoplasty or alone was one of the less commonly performed surgery in our hospital. Overall, they consisted of $7.8 \%$ of the surgeries performed over the past four years. However, the trend of this surgery is in declining phase. Pynnonen et al noted a substantial decrease in the proportion of patients undergoing surgery in a hospital setting and an increase in patients who had surgery with image guidance. ${ }^{13}$

Myringoplasty and mastoid surgeries were other surgeries performed in our institution. Both the surgeries were performed under general anesthesia. Myringoplasty was almost constantly performed whereas mastoid surgery had shown the decreasing trend. Myringoplasty/Tympanoplasty was the most common surgery performed in a study performed by Singh et al. ${ }^{14}$ They had performed surgery in $306(40.7 \%)$ ear cases, 297 (39.5\%) nasal cases and $149(19.8 \%)$ throat cases as day care basis in a period of three years.In a study performed by Eskander et al, ${ }^{15}$ in Canada, the numbers of myringoplasty (Tympanoplasty) and mastoidectomy were found to be uncommon in comparison to other surgeries. Similarly, in the United States, there was an overall downward trend in otitis media related health care use including use of ventilation tube insertion from 2001 to $2011 .{ }^{16}$ Das-Purkayastha et al in a study ontime trend analysis of mastoidectomy procedures performed in Ontariobetween 1987 and 2007observed that there was a reduction in the number of modified radical mastoidectomy and revision mastoidectomy surgeries per head of population. ${ }^{7}$ They suggested it to be due to a true reduction in prevalence of cholesteatoma. This trend explains the decreased prevalence of infectious diseases in the developed countries. They also observed that the increased number of cases performed at the University Hospital Network, Toronto (UHN) may represent a shift to sub specialization in the treatment of chronic ear disease.The reason behind the reduction in our cases is also probably due to the establishment of dedicated ear hospital in our city in recent years and the aggressive advertisement to attract the patients which coincides with their observation.

Third most common surgery performed in 2015, tonsillectomy ranked in the $7^{\text {th }}$ position in 2018. It was amongst $9.76 \%$ of all the surgeries performed in 2015 and $3.98 \%$ of all the surgeries performed in 2018 and average of $6 \%$ of all the surgeries performed overall in these four years. The trend of tonsillectomy has been decreased in a gradual manner. This study is in accordance with a study performed by Douglas et al in Scottish people. ${ }^{17}$ In a retrospective study performed for tonsillectomy, tonsillitis admissions, peritonsillar abscess admissions and deep neck space infection in Scottish people, they found that tonsillectomy rates between 1993/94 and 2015/16 were decreased by $48 \%(\mathrm{P}<0.001)$. In our study, there was $6 \%$ decrease in 4 years. However, Erickson et al in their study reported anoverall increase in rates of adenoidectomies and tonsillectomies with the surgical indications shifting from infection to upper airway obstruction. ${ }^{18}$

\section{CONCLUSION}

Our study reveals that the trend of performing major otolaryngology and head and neck surgeries in our institution is in the descending trend in the recent years after 2015. Although many developed countries have the same status in general otolaryngology, they have improved a lot in specialty and subspecialty services. Common ENT related surgeries shall be in the descending trend while 
specialty services will be ever progressing. Therefore, it is essential for the institutions to upgrade their staffs in numbers, to train their staff in different subspecialties of ENT along with construction of goodinfrastructures and procurement of state-of-the-art instruments.

\section{Limitations of the study}

This study is the study carried out in a single institution with limited number of surgeons, instruments and infrastructure. We don't have national database in our country till now. So, larger number of studies in multicentric fashion would be effective to understand the increasing or decreasing pattern of different ENT related surgeries in Nepal.

\section{REFERENCES}

1. ENT UK. Indications for Tonsillectomy: Position Paper, ENT UK 2009. London: ENT UK; 2009.

2. Eurostat (EU). Surgical operations and procedures statistics [Internet]. EU; 2018July [Cited 2019 December 6]. Available from: https://ec.europa.eu/eurostat/statistics-explained/index. php/Surgical_operations -and -procedures_statistics.

3. Neil W. History of medicine: Otorhinolaryngology. Postgrad Med J 2000; 76: 65-69. https://doi.org/10.1136/pmj.76.892.65

4. Millington AJ and Phillips JS. Current trends in tonsillitis and tonsillectomy.Ann R Coll Surg Engl 2014;96(8): 586-589. https://doi.org/10.1308/003588414X13946184901966

5. Elizabeth K, Murray J, SharlandM andSaxena SK.Changing Indications and Socio-Demographic Determinants of (Adeno) Tonsillectomy among Children in England - Are They Linked? A Retrospective Analysis of Hospital Data. PLoS ONE2014; 9(8):e103600.

https://doi.org/10.1371/journal.pone.0112887

6. Borgstrom A, Nerfeldt P, Friberg D, Sunnergren $O$ and Stalfors J. Trends and changes in pediatric tonsil surgery in Sweden 1987-2013: a population-based cohort study. Ear, nose and throat/otolaryngology Research.

7. Parikh MP, Gupta NM, Singhal A, Sarvepalli S, Muthukuru S, Lopez R, et al. National trends in inpatient admissions and outcomes among patients with esophageal foreign bodies. Gastrointestinal endoscopy 2018; 87(6) AB287-AB288.

https://doi.org/10.1016/j.gie.2018.04.1616

8. Das-Purkayastha PK, Coulson CJ, Pothier DD, Lai P and Rutka JA. Time trend analysis of mastoidectomy procedures performed in Ontario, 1987-2007. Acta Otolaryngol 2012;
132(1):16-20.

https://doi.org/10.3109/00016489.2011.617780

9. Psaltis AJ, Soler ZM, Nguyen SA and Schlosser RJ. Changing trends in sinus and septal surgery, 2007 to 2009. Int Forum Allergy Rhinol 2012; 2(5):357-361. https://doi.org/10.1002/alr.21036

10. Venkatraman G, Likosky DS, Zhou W, Finlayson SRG and Goodman DC. Trends in Endoscopic Sinus Surgery Rates in the Medicare Population. Arch Otolaryngol Head Neck Surg 2010; 136(5):426-430. https://doi.org/10.1001/archoto.2010.58

11. Mondal PJ, Saha S, Ghosh A and Sengupta M. Removal of Foreign Bodies from Esophagus with Flexible Endoscope - A Case Report. Indian J Otolaryngol Head Neck Surg 2014; 66(Suppl 1): $78-80$. https://doi.org/10.1007/s12070-011-0320-9

12. Birk M, Bauerfeind $P$, Deprez $P H$, Häfner M, Hartmann D, Hassan C, et al Removal of foreign bodies in the upper gastrointestinal tract in adults: European Society of Gastrointestinal Endoscopy (ESGE) Clinical Guideline. Endoscopy 2016; 48(5):489-496. https://doi.org/10.1055/s-0042-100456

13. Pynnonen AM and Matthew MD. Extent of Sinus Surgery, 20002009: A Population-Based Study. Laryngoscope 2014; 124(4): 820-825. https://doi.org/10.1002/lary.24335

14. Singh VP and Kalra SP. Day Care Surgery in Otolaryngology: a three-year Prospective Study. Med J Armed Forces India 2004; 60(1): 31-34.

15. Eskander A, Campisi P, Witterick IJ and Pothier DD.Consultation diagnoses and procedures billed among recent graduates practicing general otolaryngology - head \& neck surgery in Ontario, Canada.J Otolaryngol Head Neck Surg 2018; 47: 47. https://doi.org/10.1186/s40463-018-0293-8

16. Marom T, Tan A, Wilkinson GS, Pierson KS, Freeman JL and Chonmaitree $\mathrm{T}$. Trends in otitis media-related health care use in the United States, 2001-2011.JAMA Pediatr 2014; 168(1):68-75. https://doi.org/10.1001/jamapediatrics.2013.3924

17. Douglas CM, Altmyer $U$, Cottom L, Young D, Redding $P$ and Clark LJ. A 20-year observational cohort of a 5 million patient population-Tonsillectomy rates in the context of two national policy changes. Clin Otolaryngol 2019; 44(1):7-13. https://doi.org/10.1111/coa.13233

18. Erickson BK, Larson DR, St. Sauver JL, Meverden RA and Orvidas LJ. Changes in incidence and indications of tonsillectomy and adenotonsillectomy, 1970-2005. Otolaryngology - Head and Neck Surgery 2009; 140(6), 894-901. https://doi.org/10.1016/j.otohns.2009.01.044

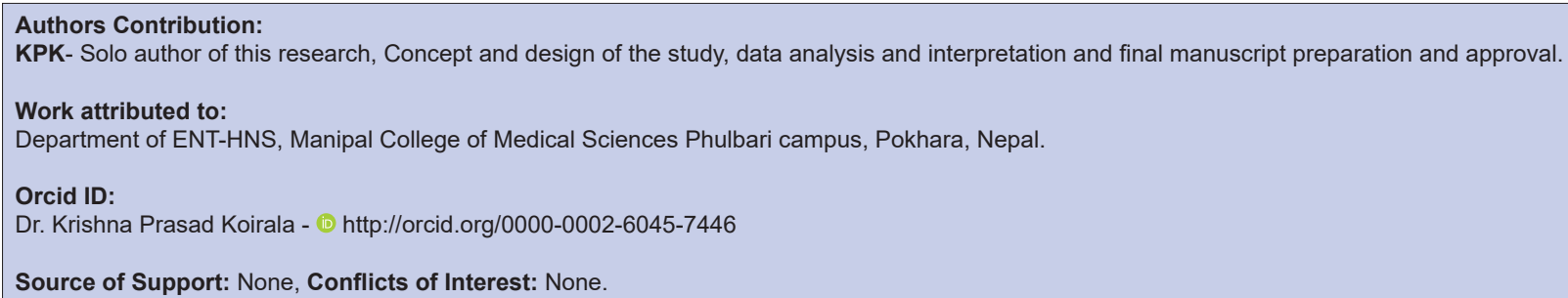

